\title{
Aspects of plant behaviour under anoxia and post-anoxia
}

\author{
M. Pfister-Sieber and R. Brändle \\ Institute of Plant Physiology, University of Berne, CH-3013 Bern, Switzerland
}

\begin{abstract}
Synopsis
All plants are able to survive anoxic periods, but the degree of tolerance shows large variation. The main injuries related to anoxia are eventually due to changes in energy metabolism. Low energy charge values indicate a cessation of many ATP consuming processes. Sugar starvation, lactic acid fermentation and proton release from leaky vacuoles are responsible for cell death. Long-term anoxia tolerance is dependent on storage products in the vicinity of sinks, on an adequate control of glycolysis, synthesis of essential proteins, and stability of membranes and organelles. However, no fundamental differences between the metabolic pathways of tolerant and non-tolerant tissues are known. It is rather a question of minor changes and the regulation of anaerobic metabolism.

Re-exposure of anoxic tissues to air may even be more detrimental than anoxia itself. These injuries are mainly due to enhanced radical generation. Lipid peroxidation processes lead to membrane damage, disintegration, and leakage of solutes. Under natural conditions plants are equipped with radicaldetoxifying systems (SOD, peroxidases and antioxidants). Natural detoxifying systems can be reduced in non-adapted plants under anoxia and they become more sensitive to post-anoxic damage. In addition, the rapid conversion of ethanol to extremely toxic acetaldehyde seems to be a cause of tissue injury and death.
\end{abstract}

\section{Introduction}

Strict anoxia is not a very obvious stress to plants since our atmosphere consists of $21 \%$ oxygen. However, on closer examination it frequently happens that plant organs, such as underground organs, soaked seeds and bulky tissues, suffer from the periodical or prolonged absence of oxygen. In addition to anoxia, re-oxygenation proves to be even more detrimental to non-adapted tissues. These so-called postanoxic effects seem to be comparable to the well known post-ischaemic injuries of human tissues (Gutteridge \& Halliwell 1990).

Anoxia occurs mostly together with flooding under natural conditions and is preceeded by less harmful hypoxic conditions. Flooding also implies additional stresses. Well characterised are effects caused by elevated carbon dioxide and ethylene concentrations (Jackson 1990; Voesenek et al. 1992). Furthermore, soil reduction gives rise to heavy metal and sulphide stress and alters nitrogen nutrition. Adapted plants, e.g. shooted amphibious plants, are able to avoid all of these stresses by efficient internal ventilation and oxygen release (Armstrong 1979; Grosse \& Bauch 1991). Ethylene mediated aerenchyma formation and supergrowth may promote avoidance strategies, as shown in maize and floating-leaved plants. Less overlapping with other stresses is expected in soaked seeds and bulky organs. Here hindered oxygen diffusion alone reflects more accurately the situation of strictly anoxic conditions. However, to obtain a clear insight into metabolic changes and tissue injuries due solely to anoxia, the use of anaerobic incubators with defined atmospheres (e.g. $85 \% \mathrm{~N}_{2}, 5 \% \mathrm{CO}_{2}, 10 \% \mathrm{H}_{2}$, Pd catalyst) is preferable.

The most evident expression of post-anoxic injury is the tissue decay observed immediately after oxygen supply is restored. This happens experimentally after 
removing tissues or plant organs from an anaerobic incubator. The time span of anaerobic incubation usually determines whether a tissues survives or dies within the reduced atmosphere or only after re-oxygenation. Large differences between species and tissues have been described (Crawford 1992).

Plant life under anoxia and subsequent post-anoxia raises the following questions:

(1) What are the causes of short- and long-term anoxia intolerance?

(2) What are the most successful strategies to improve anoxia tolerance?

(3) What are the underlying components relating to post-anoxic injuries?

Ample literature is available on metabolism under hypoxia and anoxia (Jackson et al. 1991; Drew 1992). Very little is known with respect to post-anoxic plant behaviour. Therefore, this review is restricted to more recent perspectives of anoxia research and summarises some known facts about post-anoxic injuries. It also includes a comparison between the extremely anoxia-tolerant sweet flag (Acorus calamus L.) and rather sensitive potato (Solanum tuberosum L., var. Désirée).

\section{Aspects of anaerobic metabolism}

It is likely that all higher plants are able to survive short periods without oxygen. Glycolysis, including simple $\mathrm{NADH}+\mathrm{H}$ oxidation processes, evolved before aerobic respiration and is still ubiquitously present in the plant kingdom. It might also be possible that ubiquitously distributed haemoglobin acts as a signal molecule indicating anoxia and that is responsible, therefore, for the induction of anaerobic metabolism (Appleby et al. 1988).

Several handicaps have to be overcome to survive even a day of complete oxygen deprivation. Glycolysis needs considerable amounts of stored energy, preferably carbohydrates, but mobilisation of starch can already be disturbed under anoxia. Perata et al. (1992) showed that wheat seeds fail to degrade the starch of the endosperm under anoxia. Rice is more successful. It induces $\alpha$-amylases anaerobically for starch breakdown. This capability seems to be necessary for anaerobic germination. Wheat needs exogenously applied, soluble sugars for this purpose. Carbohydrate transport out of the storage organ may also be strongly inhibited. Radioactive carbohydrates fed to the scutellum of anoxic maize never reached the root tip and roots died within $8 \mathrm{~h}$ (Saglio 1985). Successful anoxia tolerance, therefore, should avoid long distance transport of sugars and other solutes. Having carbohydrates next to the sink is not sufficient (e.g. in rhizomes, tubers, stolons) but only a prerequisite for anoxia tolerance. Potato tubers, for example, proved to be rather sensitive. They survive only about 2 to 3 days, and green parts and roots survive much less than 1 day.

The ATP required to keep anaerobic tissues alive is generated in fermentation processes. It seems that substantial growth does not take place in any tissue; cell extension in petioles and stems is possible, but no cell divisions occur in oxygenfree meristems.

Immediate effects of oxygen deprivation involve energy metabolism. Adenylate energy charge $(A E C=[\mathrm{ATP}]+0.5[\mathrm{ADP}] /[\mathrm{ATP}]+[\mathrm{ADP}]+[\mathrm{AMP}])$ drops within a few minutes or even seconds to very low values of around 0.3 , instead of $0.8-0.9$ in tissues where ATP-producing and ATP-consuming processes are equilibrated (Pradet \& Raymond 1983). Adapted tissues and organs re-establish equilibrium very rapidly, 
although overall metabolic activity is at a lower level ('anaerobic retreat'). Nonadapted potato tissue fails and runs out of ATP (Sieber \& Brändle 1991). Figure 1 shows a comparision of $A E C$ values between tolerant species ( $A$. calamus L., Phragmites australis Trin.) and the intolerant potato tuber.

In most cases anaerobic metabolism is fully dependent on fermentation energy. Moreover, at the beginning of germination of rice seeds stored nitrate can serve probably as an alternative electron acceptor as shown for exogenous nitrate (Reggiani et al. 1985, 1993). In addition, nitrate can induce nitrogen assimilating pathways (Reggiani et al. 1993). Energy is mainly produced by ethanolic fermentation, as shown in the example of $A$. calamus (Fig. 2). Fermentation usually starts with lactic acid fermentation. The fall in $\mathrm{pH}$ caused by the lactic acid subsequently

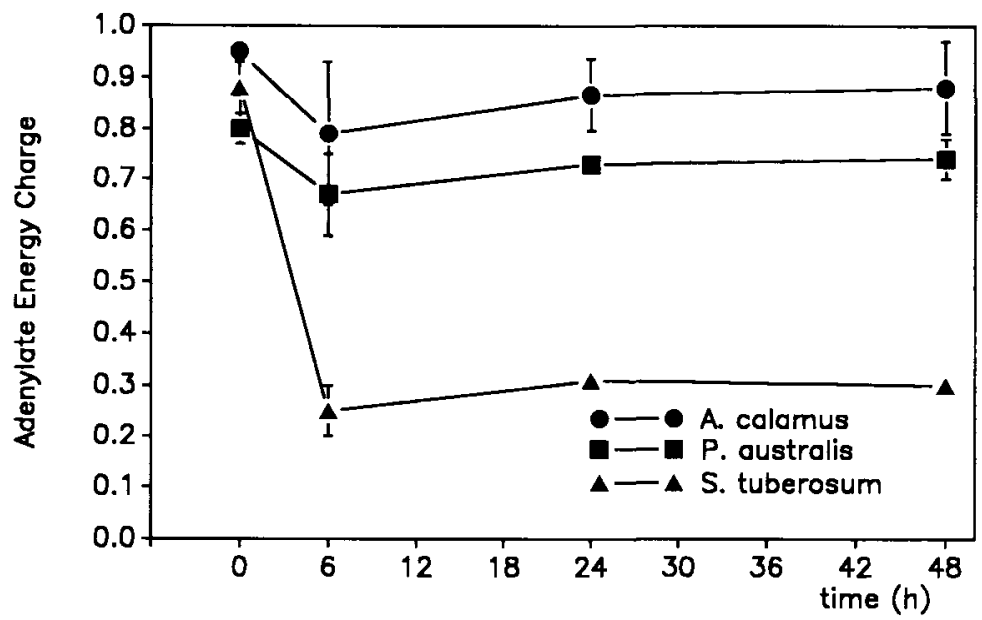

Figure 1. Adenylate energy charge of rhizomes (Acorus calamus, Phragmites australis) and tubers (Solanum tuberosum, var. Bintje) under anoxia up to $48 \mathrm{~h}$. For methods see Sieber \& Brändle (1991). $n=5 \pm$ SD.

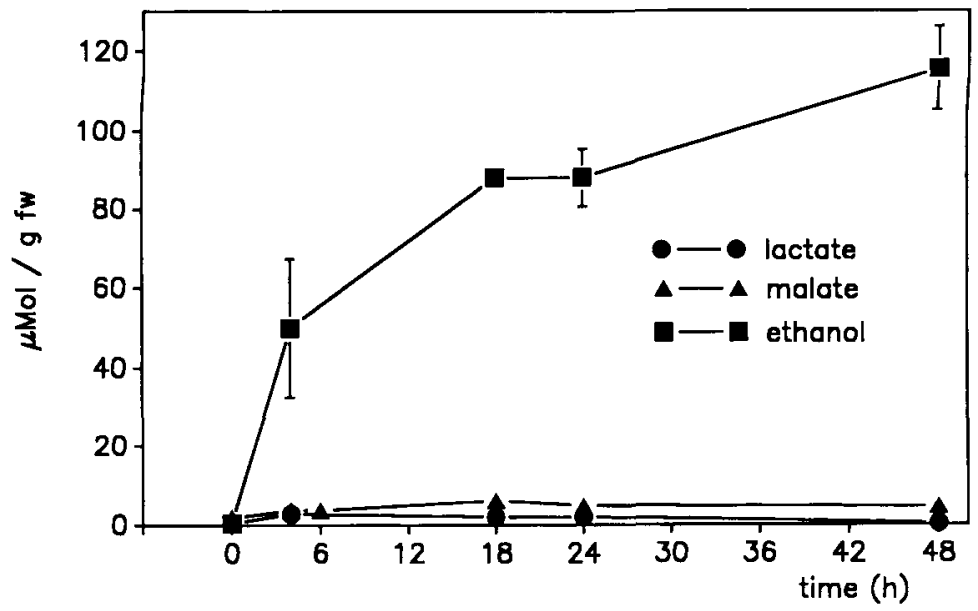

Figure 2. Ethanol, lactate and malate contents in rhizomes of Acorus calamus under anoxia. Products have been determined with test kits (Boehringer, Mannheim, Germany). $n=5 \pm \mathrm{SD}$. 
induces higher alcohol dehydrogenase activity in many tissues. However, there are exceptions. Anoxic roots of Limonium species show a large glycolytic flux to lactate (Rivoal \& Hanson 1993). Potato tubers (S. tuberosum L. var. Désirée) have substantially higher lactate dehydrogenase activities than ADH activities shortly after the onset of anoxia (Fig. 3). Accordingly, lactate, ethanol and also malate accumulate during the first hours of anoxia (Fig. 4). Malic enzyme activity is only slightly altered in potato tissues.

With regard to overall fermentation, potato tubers are less successful. They produce less ATP than A. calamus, for example (Sieber \& Brändle 1991). On the other hand they accumulate organic acids, which could reduce considerably cytoplas-

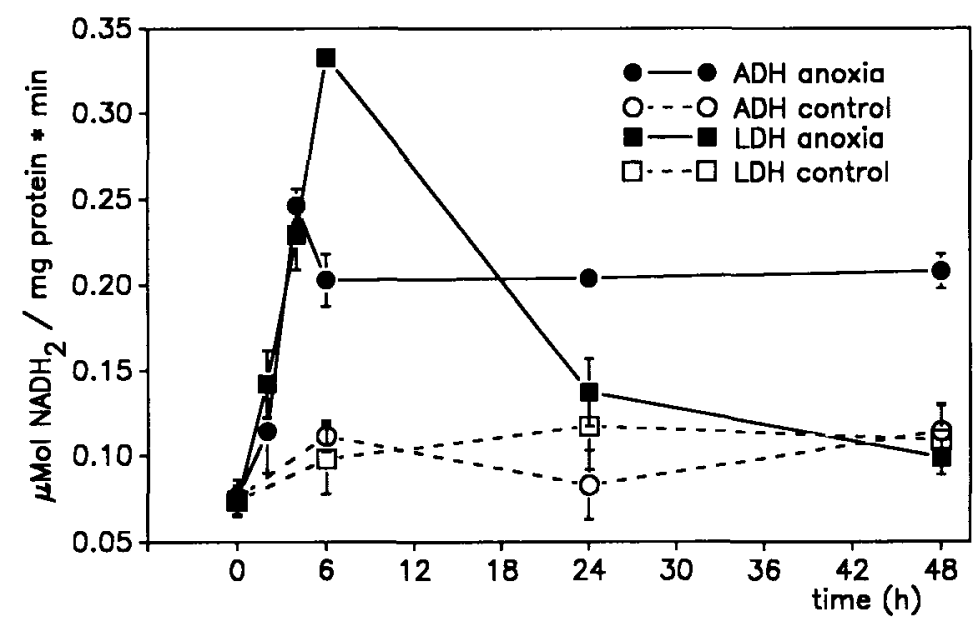

Figure 3. Alcohol and lactate dehydrogenase activity in potato tubers (Solanum tuberosum, var. Désirée) under anoxia and normoxia determined according to Sieber \& Brändle (1991). $n=5 \pm$ SD. Open symbols represent air controls.

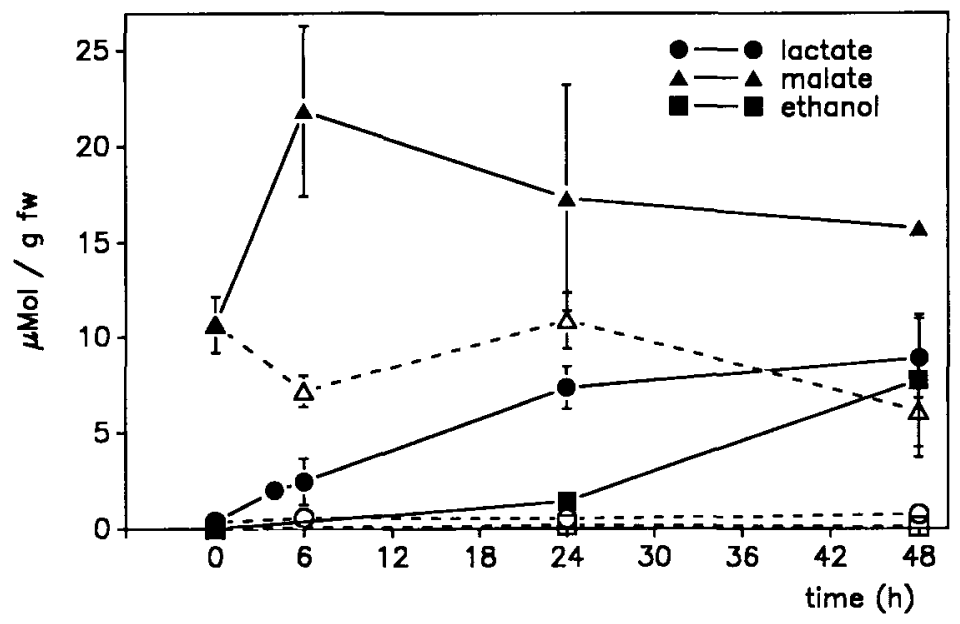

Figure 4. Ethanol, malate and lactate contents in potato tubers (Solanum tuberosum, var. Désirée) under anoxia. Products have been determined with test kits (Boehringer, Mannheim, Germany). $n=5 \pm \mathrm{SD}$. Open symbols represent air controls. 
mic $\mathrm{pH}$. Potato tissues show a $\mathrm{pH}$ drop of about 0.7 units within the first $24 \mathrm{~h}$ of anoxia, whereas $\mathrm{pH}$ decreases only by 0.2 units in $A$. calamus. Cytoplasmic acidosis, induced by proton leakage from the vacuole, has been long known to be a major reason for cell death. In non-tolerant tissues (e.g. wheat and maize) it appears that only weak, if any, alkalinisation processes occur, whereas in rice alkalinisation takes place in the cytoplasm and in the vacuole (Menegus et al. 1993). In A. calamus, high amounts of accumulated arginine could counteract the $\mathrm{pH}$ drop, but here the localisation of arginine is not yet known (Weber \& Brändle 1994).

In many non-tolerant plant species the control of glycolytic flux is impeded and production of glycolytic end products and carbon dioxide is increased, resulting in a pronounced 'Pasteur effect'. This occurs only when endogenous or exogenous carbohydrates are available. Otherwise the cells starve within a few hours. In middletolerant species (e.g. Hordeum vulgare L.) pyruvate is converted to additional products other than ethanol and lactate. Alanine (by transamination of aspartate), malate and succinate occur at the beginning of anoxia (Good \& Muench 1993). Diversification of glycoloytic end products may be helpful to avoid injury, but the quantitative significance is not known yet. Under prolonged anoxia ethanol is the most abundant product, even in the most tolerant plants. Moreover, these plants are able to release ethanol very easily into their surroundings. The assumption that ethanol is toxic under certain conditions is still not generally accepted, although some rather sensitive tissues exist (Perata \& Alpi 1991). Furthermore, the removal of volatile products (e.g. ethanol and acetaldehyde) increases anoxia tolerance in the sensitive chickpea, Cicer arietinum L. (Crawford \& Zochowski 1984). It might be that different tissues have different sensitivities and that acetaldehyde rather than ethanol is toxic. Transgenic tobacco plants, however, with an additional PDC (pyruvate decarboxylase) gene from Zymomonas nobilis produce and release excessive amounts of acetaldehyde under anoxia (Bucher et al. 1994). Unfortunately, it was not possible to regenerate transgenic potato plants from transformed tuber disks, probably because of the acetaldehyde produced and accumulated in the fleshy and dense tissue (Bucher, personal communication).

Cell maintenance under anoxia of more than a few hours requires the synthesis or stability of essential macromolecules (RNAs, proteins and lipids). Normal protein synthesis almost ceases in non-tolerant species (e.g. maize, wheat) in which only about 10-20 newly formed, stress proteins appear. The same happens in tolerant tissues (e.g. marsh plant rhizomes). Additionally, many of the 'aerobic' proteins are still synthesised, albeit only in small quantities. The stress proteins have been partially characterised and they consist mainly of glycolysis-related enzymes (Andrews et al. 1993; Bucher \& Kuhlemeier 1993). The best investigated is alcohol dehydrogenase $(\mathrm{ADH})$, although $\mathrm{ADH}$ is not the rate-limiting enzyme of ethanolic fermentation, which seems rather to be pyruvate decarboxylase (PDC). Furthermore, Mujer et al. (1993) consider that most of the induced stress proteins are of little importance when comparing tolerant with sensitive Echinochloa species. They suggest that another set of genes, whose products are not among the major anaerobic stress proteins, could contribute much more to anoxia tolerance.

However, so far no fundamentally different pathway of intermediate and protein metabolism between tolerant and non-tolerant species has been discovered. There probably exist only various minor adaptions which decide between short- and long-term anoxia survival. 
This assumption is supported by looking at the strategy of lipid preservation. Lipid synthesis is very costly in terms of ATP, and under oxygen deprivation lipid desaturation hardly occurs. Therefore, lipid preservation is the most efficient way to maintain functional membranes. In fact, the content and the composition of polar lipids is much more stable in rhizomes of $A$. calamus and Schoenoplectus lacustris L. than in the less tolerant rhizomes of the dryland species Iris germanica L. (Henzi \& Brändle 1993). Some individual lipids of wetland species change their internal composition slightly during anoxia. Usually linolenic acid (18:3) decreases and is replaced by linoleic $(18: 2)$ and oleic acid (18:1). In $A$. calamus the composition recovers within two days of re-aeration. Lipids of adapted species have obviously a high stability and only limited decomposition of lipids (e.g. liberation of free fatty acids, as in $I$. germanica) occurs. Organelles are stable too, and thus can function for longer periods of anoxia, as has been shown for rice mitochondria (Couée et al. 1992). A. calamus survives up to three months of complete anoxia, whereas I. germanica dies within 14 days. In the latter species the lipids are completely destroyed after 21 days of anoxia.

\section{Post-anoxic effects on plant metabolism}

As mentioned before, restoration of normal $\mathrm{O}_{2}$ concentrations can be deleterious to plant tissues. Oxygen toxicity is proposed to be the principle mechanism of postanoxic injury. Active oxygen species, such as the superoxide radical $\left(\mathrm{O}_{2}^{-}\right)$, hydrogen peroxide $\left(\mathrm{H}_{2} \mathrm{O}_{2}\right)$ and the hydroxyl radical $\left(\mathrm{OH}^{\circ}\right)$, are all extremely cytotoxic to plant cells (Scandalios 1993). Hydrogen peroxide reacts in the presence of iron ions to form the most dangerous hydroxyl radical. In flooded tissues, for example, there is ample reduced iron available. All active oxygen species attack DNA, proteins, and especially lipids.

Conditions favouring $\mathrm{O}_{2}$ radical generation, like low energy charge, high reducing equivalent levels and saturated electron transport components, usually exist in anoxic tissue (Van Toai \& Bolles 1991). Therefore a burst of active oxygen species occurs when aerobic conditions are restored, with the result of immediate post-anoxic injury in non-adapted tissues.

The most susceptible molecules for radical attack are polyunsaturated fatty acids, PUFA (Ursini et al. 1991). Free radical-mediated lipid peroxidation of unsaturated fatty acids is a chain reaction occurring mainly in biomembranes, where the PUFA content is relatively high. Lipid peroxidation is linked to severe membrane damage, e.g. increased ion permeability, loss of fluidity, leakage and inactivation of membrane enzymes and receptors. Intracellular membrane damage affects cell organelles. Typical lipid peroxidation products are malondialdehyde (MDA), ethane and also ethylene. MDA derives mainly from the peroxidation of PUFA with three to six double bonds (Pryor et al. 1976). MDA is biologically active and binds to DNA and proteins. Ethane is probably the most sensitive indicator of peroxidative membrane damage. Furthermore, it is very easily detectable by head space gas chromatography. It is one of the products of radical induced linolenic acid (C18:3) degradation (Konze \& Elstner 1978). Ethylene is usually formed from its precursor ACC in the presence of oxygen but also by lipid peroxidation (Bousquet \& Thimann 1983). ACC can also be conjugated to Malonyl-ACC. The latter is generally thought to be biologically inactive, but under certain conditions ACC is liberated and subsequently 
forms ethylene (Jiao et al. 1986). ACC and M-ACC accumulate in wetland plant tissue (Studer \& Brändle 1987).

Lipid peroxidation processes have been investigated under different stresses, but so far little work has been done in the context of anoxic and post-anoxic tissues. For example, re-exposure of rhizomes to air after prolonged anoxia induced the formation of peroxidation end products in terrestrial species like $I$. germanica, less in the related wetland species $I$. pseudacorus $\mathrm{L}$., and hardly at all in the most tolerant. A. calamus (Hunter et al. 1983; Henzi \& Brändle 1993).

Potato tubers react very sensitively to oxygen deprivation (Sieber \& Brändle 1991) and some important observations refering to its post-anoxic energy metabolism and survival are listed below $(A E C=$ adenylate energy charge):

$\begin{array}{cccc}\begin{array}{c}\text { Anoxic } \\ \text { pretreatment } \\ \text { (h) }\end{array} & \begin{array}{c}\text { Post-anoxic } \\ A E C\end{array} & \begin{array}{c}\text { Post-anoxic } \\ \mathrm{O}_{2} \text {-uptake } \\ \left(\mu 1 \mathrm{~g}^{-1} \mathrm{fw}\right)\end{array} & \begin{array}{c}\text { Survival and } \\ \text { growth }\end{array} \\ & 0.90 \pm 0.06 & 51 \pm 7 & \\ & 0.79 \pm 0.09 & 23 \pm 4 & 100 \% \\ & 0.83 \pm 0.08 & 18 \pm 4 & 100 \% \\ \text { (issue turgescent) } & 0.76 \pm 0.08 & 15 \pm 10 & <100 \% \\ & \text { or } & \text { or } & \text { occasional } \\ \text { (n) mushy) } & 0.30 \pm 0.04 & 0 & 0 \%\end{array}$

Potatoes (S. tuberosum L., var. Désirée) obviously lose viability between day 2 and day 3. Viability is dependent on $A E C$ restoration under post-anoxia and a remaining respiration capacity (for $A E C$ under anoxia see Figure 1). The decrease in respiration capacity may reflect membrane disintegration of mitochondria.

Potato tubers show the whole range of peroxidation products after re-exposure to air. Malondialdehyde (Fig. 5) content increases with anaerobic pretreatment and potato tubers show a considerable burst of ethane (Fig. 6), mostly within the first $2 \mathrm{~h}$ of post-anoxic treatment. The release of ethylene (Fig. 7) is more uniform because it is partially due to accumulated ACC and M-ACC. Both precursors are

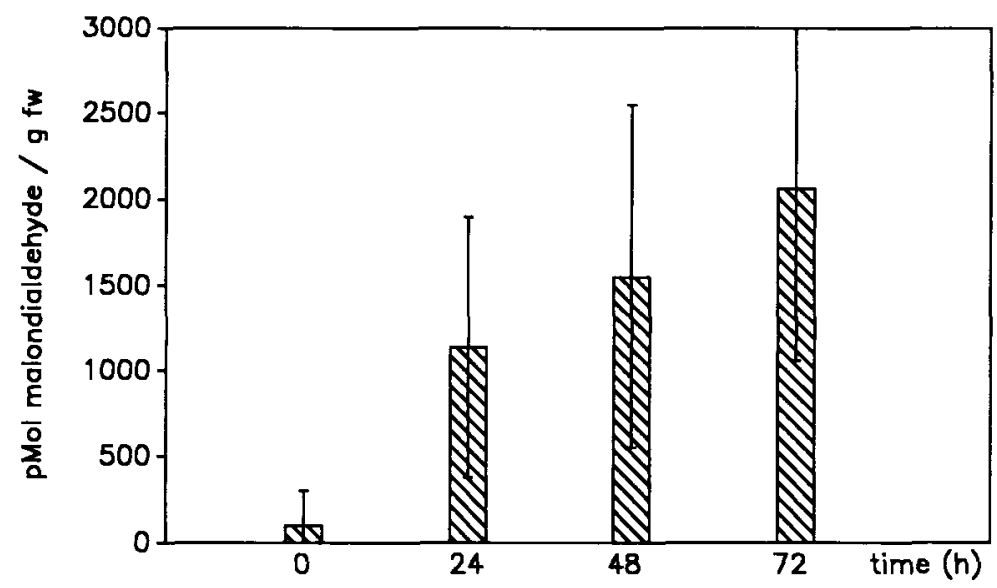

Figure 5. Increase of malondialdehyde contents in potato tubers (Solanum tuberosum, var. Désirée) after $5 \mathrm{~h}$ of post-anoxic treatment. Anoxic pretreatment 24,48 and $72 \mathrm{~h}$. Malondialdehyde was estimated according to Pryor et al. (1976). $n=7 \pm$ SD. 


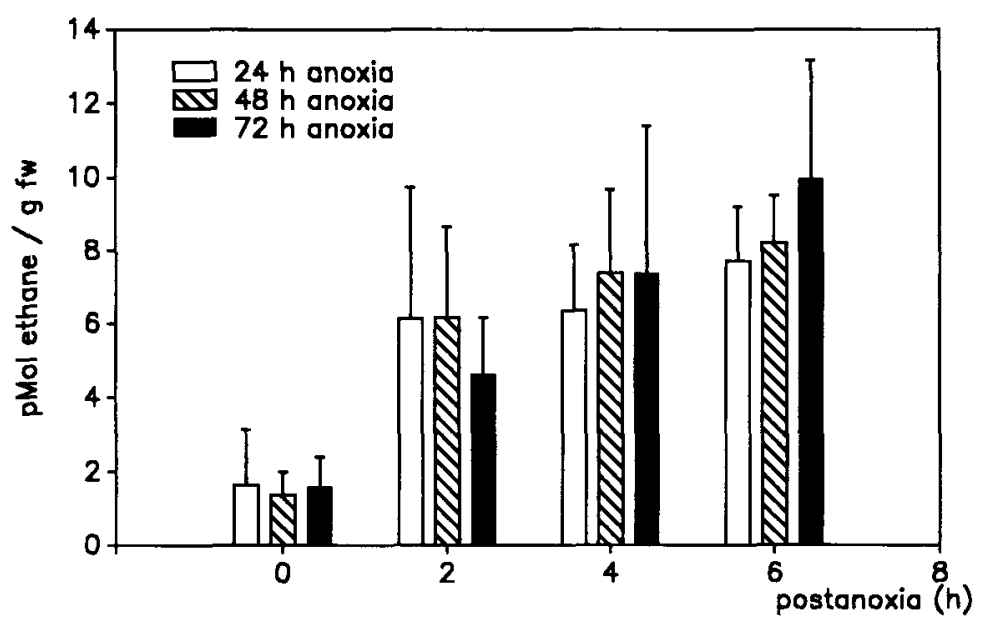

Figure 6. Ethane release of potato tubers (Solanum tuberosum, var. Désirée) under post-anoxia. Ethane was estimated by head space GC on a Porapak Q column. $n=7 \pm \mathrm{SD}$. Air controls are less than $1 \mathrm{pM} \mathrm{g}^{-1} \mathrm{fw}$.

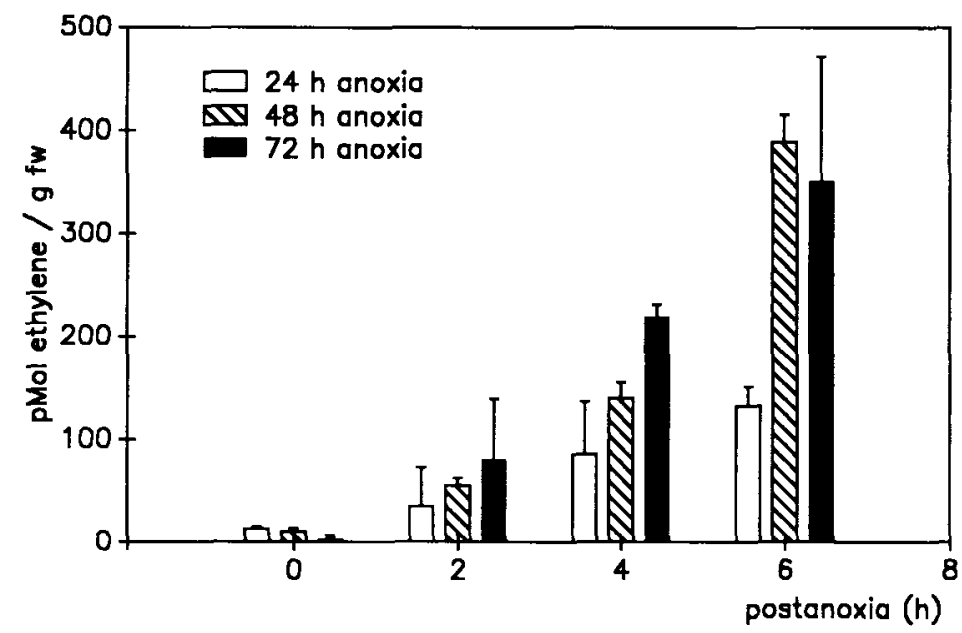

Figure 7. Ethylene release of potato tubers (Solanum tuberosum, var. Désirée) under post-anoxia. Method as above. $n=7 \pm \mathrm{SD}$. Air controls are less than $20 \mathrm{pM} \mathrm{g}^{-1} \mathrm{fw}$.

converted to ethylene when oxygen is available. The main source seems to be M-ACC (Fig. 8).

Several radical-destroying systems have evolved in nature to avoid toxicity of dioxygen. Antioxidants, e.g. ascorbate, $\alpha$-tocopherol (Vitamin E), glutathione and radical-scavenging enzymes, e.g. superoxide dismutase, ascorbate peroxidase and catalase may contribute to minimising radical-induced damage. Since $\alpha$-tocopherol is incorporated into membranes where most of the PUFA occur, it may act directly as a chain breaker of lipid peroxidation (Spychalla \& Desborough 1990).

There is little information available relating post-anoxic stress and radicaldestroying metabolism. For example, short anoxic pre-treatment (1-2 h) of Glycine 


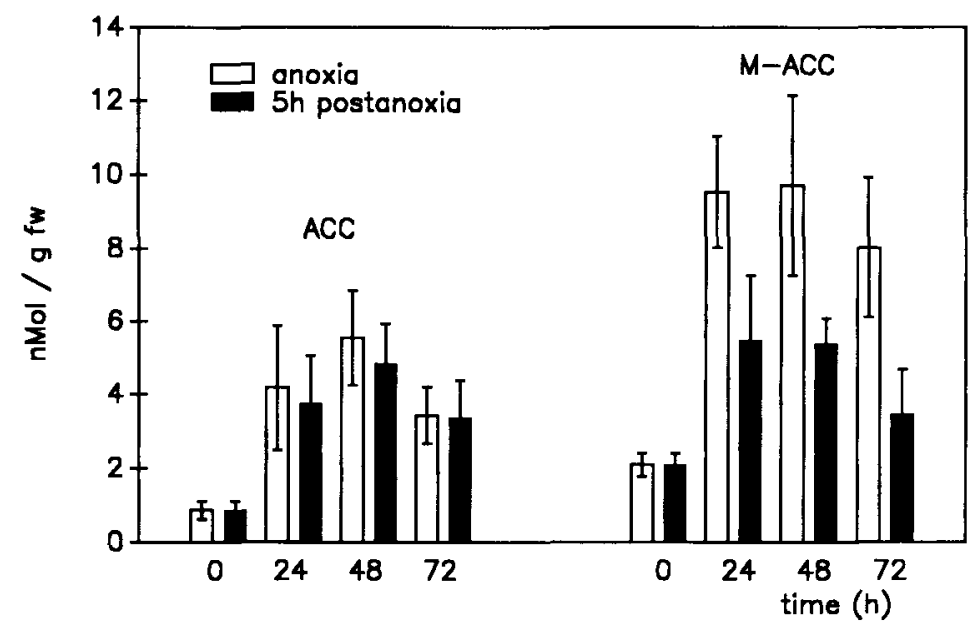

Figure 8. ACC and M-ACC contents of potato tubers (Solanum tuberosum, var. Désirée) under anoxia and after $5 \mathrm{~h}$ post-anoxia. For methods see Studer \& Brändle (1987). $n=7 \pm \mathrm{SD}$.

$\max$ root tips leads to more severe tissue damage than $3-5 \mathrm{~h}$ anoxic pre-treatment. The shorter pre-treatment shows higher radical formation and lower SOD-activities. In this case it is obvious that the slightly prolonged anoxic pre-treatment favours the ability to cope with post-anoxic stress (Van Toai \& Bolles 1991). In rhizomes of the anoxia-tolerant wetland species I. pseudacorus, post-anoxic SOD activities increase continously during anoxia, ending up with a 13 -fold increase after 28 days. This is not the case in the less tolerant I. germanica (Monk et al. 1987a). It seems that in some anoxia-adapted plants the 'oxygen protecting system' is amplified before the restoration of oxygen supply. This can be considered as the most efficient detoxification strategy.

Furthermore, chickpea seedlings (Cicer arietinum L.) kept for $48 \mathrm{~h}$ under anoxia showed less survival and an elevated $\mathrm{K}^{+}$leakage in comparison to seedlings treated with ascorbic acid before re-exposure to air (Crawford \& Wollenweber-Ratzer 1992). In potatoes, a protective effect of ascorbic acid also occurs. The infiltration of ascorbic acid solution before re-aeration leads to considerable inhibition of lipid peroxidation. The release of volatile producte (e.g. ethylene) decreases, as shown in Figure 9.

Submersed rice seedlings seem to have a reduced protection against oxidative stress. This evolves in two steps only after seedling transfer into air. The levels of the antioxidative enzymes increase rather slowly within $24 \mathrm{~h}$, reaching approximately the level of the air controls. Moreover, in contrast to the slow accumulation of enzyme activities, there is a rapid 7 -fold increase of glutathione, which could act temporarily as a radical-scavenging mechanism (Ushimaru et al. 1992).

In addition, the rapid conversion of anaerobically accumulated ethanol to acetaldehyde under post-anoxia may be another reason for post-anoxic injury (Studer \& Brändle 1988). Two pathways of ethanol oxidation have been proposed: the rather slow NAD-dependent ADH-reaction, and the fast peroxidation of ethanol by a catalase reaction. Monk et al. (1987b) showed a correlation between high postanoxic catalase activity and anoxia intolerance in three species (Glyceria maxima, Hartm. Holmberg, Juncus effusus L. and I. germanica), while three anoxia tolerant 


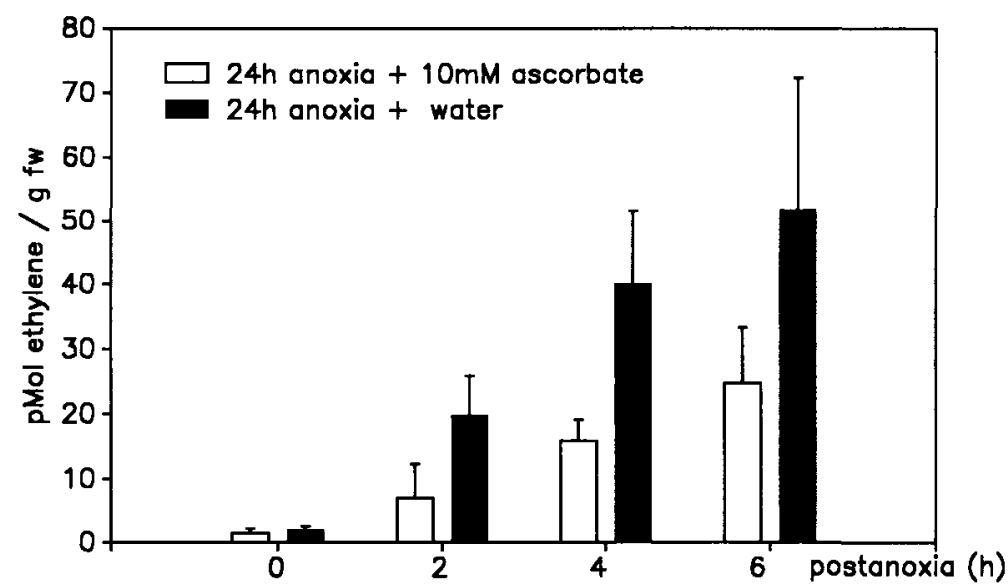

Figure 9. Post-anoxic ethylene release of potato tubers (Solanum tuberosum, var. Désirée). The tubers were infiltrated with $10 \mathrm{mM}$ ascorbic acid or water before re-aeration. Method as mentioned before. $n=7 \pm \mathrm{SD}$.

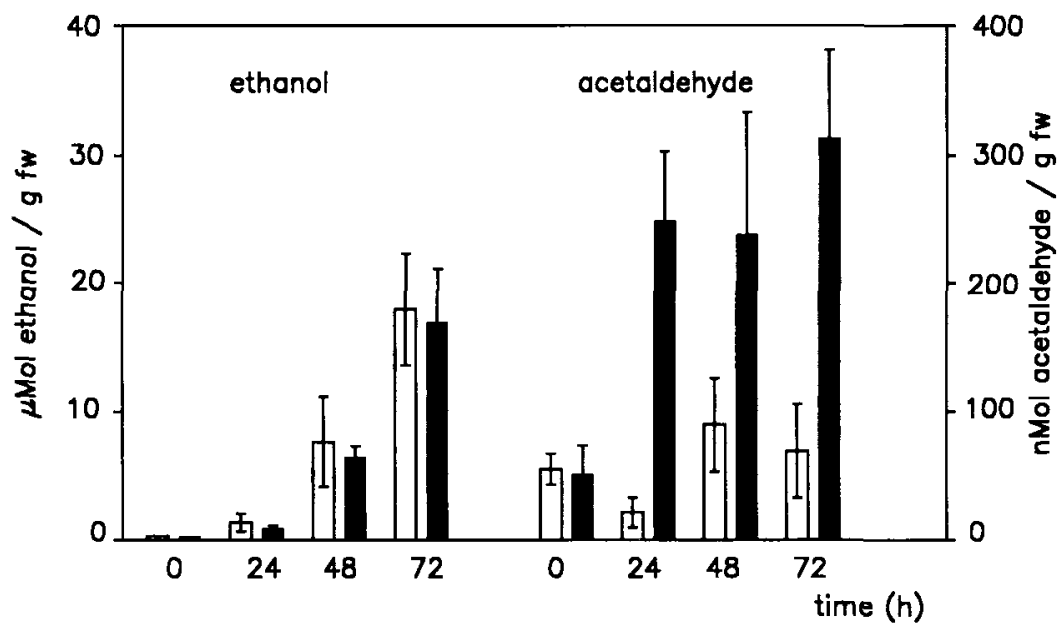

Figure 10. Ethanol and acetaldehyde content of potato tubers (Solanum tuberosum, var. Désirée) under anoxia and after $5 \mathrm{~h}$ post-anoxia. Anoxic pretreatment 24, 48 and $72 \mathrm{~h}$. Both products were determined enzymatically with test kits (Boehringer, Mannheim, Germany). $n=5 \pm \mathrm{SD}$.

species (A. calamus, S. lacustris and $I$. pseudacorus) had stable catalase activities. The non-tolerant potato tubers show the same behaviour as rhizomes of non-tolerant species. Acetaldehyde content of tubers is low under anoxia but when re-aerated a large burst of acetaldehyde takes place (Fig. 10). However, the contribution of acetaldehyde to post-anoxic injury has never been quantified, although acetaldehyde can be very harmful to plants since it produces cross-linkages between proteins.

\section{Conclusions}

(1) Anoxia exists in nature, through the flooding of underground organs, the soaking of seeds and hindered oxygen diffusion in bulky organs. 
(2) Flooding-resistant plants make use of morphological and physiological strategies to avoid anoxia whenever possible.

(3) All plant organs are able to survive short-term anoxia. Fermentation processes developed early in evolution and are still ubiquitously present.

(4) Only very few organs, such as wetland plant rhizomes and, with restrictions, some seeds (rice, Echinochloa spp.), are long-term anoxia-tolerant and persist through several weeks or even months.

(5) Long-term anoxia tolerance is due to a set of physiological and biochemical modifications. The most important are listed below:

Adequate carbohydrate supply to sustain long-lasting fermentation processes.

Control of energy metabolism, e.g. maintenance of high $A E C$ values and therefore equilibrium between ATP-producing and ATP-consuming processes, albeit at a lower level.

Priority to ethanolic fermentation and release of ethanol. Eventually diversification of glycolytic end products.

Avoidance of severe $\mathrm{pH}$ drops ('cytoplasmic acidosis') by alkalinisation processes. Continued synthesis of essential proteins and preservation of unsaturated fatty acids and lipids to improve organelle stability and function.

(6) The primary cause of post-anoxic injury of non-tolerant tissues is the formation of radicals $\left(\mathrm{O}_{2}^{-}, \mathrm{OH}^{*}\right)$ and/or the formation of a surplus of acetaldehyde.

(7) Tolerant plants counteract radical formation by reinforced detoxifying mechanisms (e.g. SOD as an anaerobically synthesised protein, antioxidants). Exogenously supplied antioxidants suppress lipid peroxidation considerably.

(8) Polyunsaturated fatty acids are the most sensitive points of attack. Lipid peroxidation is reduced in tolerant plant organs.

(9) Most of the fundamental facts of anoxia tolerance or non-tolerance have been well investigated. Less is known about the underlying mechanisms of metabolic regulation. Knowledge of basic processes under post-anoxia is extremely scarce, and research should be intensified in this area in the near future.

\section{Acknowledgements}

We thank Dr Fleming, M. Weber and G. Ferch (Bern) for helpful comments, and the Swiss National Foundation for financial support (No. 31-28494.90).

\section{References}

Andrews, D. L., Cobb, B. G., Johnson, J. R. \& Drew, M. C. 1993. Hypoxic and anoxic induction of alcohol dehydrogenase in roots and shoots of seedlings of Zea mays. Plant Physiology 101, 407-14.

Appleby, C. A., Bogusz, D., Dennis, E. S. \& Peacock, W. J. 1988. A role for haemoglobin in all plant roots? Plant, Cell and Environment 11, 359-67.

Armstrong, W. 1979. Aeration in higher plants. Advances in Botanical Research 7, $225-332$.

Bousquet, J. F. \& Thimann, K. V. 1983. Lipid peroxidation forms ethylene from ACC and may operate in leaf senescence. Proceedings of the National Academy of Sciences, USA 81, 1724-7.

Bucher, M. \& Kuhlemeier, C. 1993. Long-term anoxia tolerance: Multilevel regulation of gene expression in the amphibious plant Acorus calamus L. Plant Physiology 103, 441-8.

Bucher, M., Brändle, R. \& Kuhlemeier, C. 1994, Ethanolic fermentation in transgenic tobacco expressing Zymomonas mobilis pyruvate decarboxylase. EMBO Journal 13, (in press).

Couée, I., Defontaine, S., Carde, J.-P. \& Pradet, A. 1992. Effects of anoxia on mitochondrial biogenesis in rice shoots. Plant Physiology 101, 7-12.

Crawford, R. M. M. 1992. Oxygen availability as an ecological limit to plant distribution. Advances in Ecological Research 23, 93-185.

Crawford, R. M. M. \& Wollenweber-Ratzer, B. 1992. Influence of L-ascorbic acid on post-anoxic growth and survival of chickpea seedlings (Cicer arietinum L.). Journal of Experimental Botany 43, 703-8. 
Crawford, R. M. M. \& Zochowski, Z. M. 1984. Tolerance of anoxia and ethanol toxicity in chickpea seedlings (Cicer arietinum L.). Journal of Experimental Botany 35, 1482-80.

Drew, M. C. 1992. Soil aeration and plant root metabolism. Soil Science 154, 259-68.

Good, A. G. \& Muench, D. G. 1993. Long-term anaerobic metabolism in root tissue. Plant Physiology 101, 1163-8.

Grosse, W. \& Bauch, C. 1991. Gas transfer in floating leaved plants. Vegetatio 97, 185-92.

Gutteridge, J. M. C. \& Halliwell, B. 1990. Reoxygenation injury and antioxidant protection: a tale of two paradoxes. Archives of Biochemistry and Biophysics 283, 223-6.

Henzi, T. \& Brändle, R. 1993. Long term survival of rhizomatous species under oxygen deprivation. In Jackson, M. B. \& Black, C. (Eds) Interacting stresses on plant in a changing climate, pp. 305-314. Heidelberg: Springer Verlag.

Hunter, M. S., Hetherington, A. A. \& Crawford, R. M. M. 1983. Lipid peroxidation - a factor in anoxia intolerance in Iris species? Phytochemistry 22, 1145-7.

Jackson, M. B. 1990. Hormones and developmental changes in plants subjected to submergence or soil waterlogging. Aquatic Botany 38, 49-72.

Jackson, M. B., Davies, D. D. \& Lambers, H. (Eds) 1991. Plant life under oxygen deprivation. The Hague: SPB Academic Publishing.

Jiao, X.-Z., Philosoph-Hadas, S., Su, L.-Y. \& Yang, S. F. 1986. The conversion of 1-(malonylamino) cyclopropane-1-carboxylic acid to 1-aminocyclopropane-1-carboxylic acid in plant tissues. Plant Physiology 81, 637-41.

Konze, J. R. \& Elstner, E. T. 1978. Ethane and ethylene formation in mitochondria as indication of aerobic lipid degradation in response to wounding of plant tissues. Biochimica Acta 218, 213-21.

Menegus, F., Cattaruzza, L., Mattana, M., Beffagna, N. \& Ragg, E. 1991. Response to anoxia in rice and wheat seedlings. Plant Physiology 95, 767-7.

Monk, L. S., Fagerstedt, K. V. \& Crawford, R. M. M. 1987a. Superoxide dismutase as an anerobic polypeptide. Plant Physiology 85, 1016-20.

Monk, L. S., Brändle, R. \& Crawford, R. M. M. 1987b. Catalase activity and post-anoxic injury in monocotyledonous species. Journal of Experimental Botany 38, $233-46$.

Mujer, C. V., Rumpho, M. E., Lin, J.-J. \& Kennedy, R. A. 1993. Constitutive and inducible aerobic and anaerobic stress proteins in the Echinochloa complex and rice. Plant Physiology 101, 217-26.

Perata, P. \& Alpi, A. 1991. Ethanol-induced injuries to carrot cells. Plant Physiology 95, 748-52.

Perata, P., Pozueta, J., Akazawa, T. \& Yamaguchi, J. 1992. Effect of anoxia on starch breakdown in rice and wheat seeds. Planta 188, 611-8.

Pradet, A. \& Raymond, P. 1983. Adenine nucleotide ratios and adenylate energy charge in energy metabolism. Annual Review of Plant Physiology 34, 199-224.

Pryor, W. A., Stanley, J. P. \& Blair, E. 1976. Autooxidation of polyunsaturated fatty acids: a suggested mechanism for the formation of TBA-reactive materials from prostaglandine like endoperoxides. Lipids 11, 370-9.

Reggiani, R., Brambilla, I. \& Bertani, A. 1985. Effect of exogenous nitrate on anaerobic metabolism in excised rice roots. I. Nitrate reduction and pyridine nucleotide pools. Journal of Experimental Botany 36, 1193-1199.

Reggiani, R., Mattana, M., Aurisano, N. \& Bertani, A. 1993. Utilization of stored nitrate during anaerobic germination of rice seeds. Plant Cell Physiology 34, 379-83.

Rivoal, J. \& Hanson, A. D. 1993. Evidence for a large and sustained glycolytic flux to lactate in anoxic roots of some members of the halophytic genus Limonium. Plant Physiology 101, 553-60.

Saglio, P. H. 1985. Effect of path or sink anoxia on sugar translocation in roots of maize seedlings. Plant Physiology 77, 285-90.

Scandalios, J. G. 1993. Oxygen stress and superoxide dismutases. Plant Physiology 101, 7-12.

Sieber, M. \& Brändle, R, 1991. Energy metabolism in rhizomes of Acorus calamus L. and in tubers of Solanum tuberosum L. with regard to their anoxia tolerance. Botanica Acta 104, 279-82.

Spychalla, J. P. \& Desborough, S. L. 1990. Superoxide dismutase, catalase, and $\alpha$-tocopherol content of stored potato tubers. Plant Physiology 94, 1214-8.

Studer, Ch. \& Brändle, R. 1987. Ethanol, acetaldehyde, ethylene release and ACC concentrations of rhizomes from marsh plants under normoxia, hypoxia and anoxia. In Crawford, R. M. M. (Ed.) Plant life in aquatic and amphibious habitats, pp. 293-301. Oxford: Blackwell.

Studer, Ch. \& Brändle, R. 1988. Post-anoxic effect of ethanol in rhizomes of Glyceria maxima (Hartm.) Holmberg, Iris germanica L. and Phragmites australis (Cav.) Trin. Botanica Helvetica 98, 111-21.

Ursini, F., Maiorino, M. \& Sevanian, A. 1991. Membrane hydroperoxides. In Sies, H. (Ed.) Oxidative stress: oxidants and antioxidants, pp. 319-36. London-New York: Academic Press.

Ushimaru, T., Shibasaka, M. \& Tsuji, H. 1992. Development of the $\mathrm{O}_{2}^{-}$-Detoxification system during adaptation to air of submerged rice seedlings. Plant Cell Physiology 33, 1065-71.

Van Toai, T. T. \& Bolles, C. S. 1991. Postanoxic injury in Soybean (Glycine max) seedlings. Plant Physiology 97, 588-92.

Voesenek, L. A. C. J., Van der Sman, A. J. M., Harren, F. J. M. \& Blom, C. W. P. M. 1992. An amalgamation between hormon physiology and plant ecology: a review on flooding resistance and ethylene. Journal of Plant Growth Regulation 11, 171-88. 